\title{
OS DESAFIOS ENFRENTADOS POR MICROEMPRESAS DO VAREJO PARA A IMPORTAÇÃO DE BENS DE CONSUMO DA CHINA
}

\author{
Ricardo Klazer Fraga \\ Bacharel em Administração. Centro Universitário Metodista \\ Andrea Sander \\ Professor Mestre. Centro Universitário Metodista
}

\section{RESUMO}

Tendo como premissas básicas o crescimento do número de microempresas e o crescimento da participação dessas microempresas no cenário econômico nacional atual, o presente trabalho buscou identificar os desafios que são enfrentados por microempresas do varejo para a importação de bens de consumo da China. O referencial teórico que deu embasamento ao trabalho apoiou-se em autores consagrados, abordando temas como comércio internacional, aspectos culturais de Brasil e China, além de uma abordagem sobre os procedimentos aduaneiros adotados pelo governo Brasileiro e um panorama sobre a carga tributária incidente sobre as importações de bens de consumo. A pesquisa teve caráter descritivo, com abordagem qualitativa, sendo o levantamento de campo o procedimento utilizado na coleta de dados e entrevistas realizadas com gestores de microempresas que importam bens de consumo da China. Para tal coleta, foi elaborado um roteiro semiestruturado com perguntas abertas que permitiu que os entrevistados, três microempresários sediados nas cidades de Canoas (RS); Curitiba (PR); e em Maracajú (MS) expusessem seu ponto de vista acerca do tema pesquisado, sendo estas respostas passaram por análise interpretativa. Os resultados obtidos foram que os microempresários não percebem a diferença cultural e linguística como um problema a ser enfrentado na negociação com fornecedores chineses. Verificou-se que a carga tributária incidente nos processos de importação de bens de consumo é responsável por mais da metade do valor final das mercado- 
rias e que existe certa dificuldade para os microempresários brasileiros conseguirem o seu registro para poderem operar no comércio exterior. Palavras-Chave: Comércio Internacional. Importação. China. Microempresas.

\section{THE CHALLENGES FACING RETAIL MICROENTERPRIS- ES FOR THE IMPORT OF CONSUMER GOODS FROM CHINA}

\section{ABSTRACT}

Based on the basic assumptions of the growth of the number of micro -enterprises and the growth of the participation of these micro-enterprises in the current national economic scenario, the present work sought to identify the challenges faced by micro-enterprises of the retail for the import of consumer goods from China. The theoretical framework that supported the work was based on well-established authors, addressing topics such as international trade, cultural aspects of Brazil and China, as well as an approach on customs procedures adopted by the Brazilian government and an overview of the tax burden on imports of consumer goods. The research had a descriptive character, with a qualitative approach, being the field survey the procedure used in the data collection and interviews conducted with managers of microenterprises that import consumer goods from China. For this collection, a semistructured roadmap was developed with open questions that allowed the interviewees, three microentrepreneurs based in the cities of Canoas (RS); Curitiba (PR); and in Maracajú (MS) to present their point of view about the researched subject, being these answers passed through interpretative analysis. The results obtained were that the microentrepreneurs do not perceive the cultural and linguistic difference as a problem to be faced in the negotiation with Chinese suppliers. It was verified that the tax burden on the importation of consumer goods accounts for more than half of the final value of the goods and that there is some difficulty for Brazilian microentrepreneurs to obtain their registration in order to be able to operate in foreign trade.

KEYWORDS: International Trade. Import. China. Microenterprises.

\section{INTRODUÇÃO}

A partir da década de 90 o mercado brasileiro se abriu para o comércio internacional, com crescimento das exportação 
de commodities e importação de bens de consumo. $\mathrm{O}$ avanço na internacionalização levou as empresas brasileiras buscarem opções estratégicas de inserção no mercado internacional em países com os quais o Brasil possui relações comerciais e diplomáticas. Em 2001, com a adesão da China à Organização Mundial do Comércio, se consolidou a abertura econômica do país mais populoso mundo, que passou a ser um importante parceiro comercial do Brasil. Apesar do crescimento e da importância que a participação no mercado internacional tem para as empresas, ainda há dificuldades a serem enfrentadas pelos empresários no Brasil, como a burocracia, a carga tributária, problemas logísticos, como portos e aeroportos com elevados custos operacionais, rodovias e ferrovias sucateadas, além das variações cambiais que são fator de desestabilidade para o comercio nacional.

O comércio exterior é fundamental no desenvolvimento econômico dos países. Nesta área se destacam as importações, pois atendem o mercado interno de produtos e insumos que não são produzidos em quantidade suficiente, ou são produzidos, mas não têm preços competitivos, ou até mesmo que não existem no país para atender à demanda interna. As importações trazem aos países parceiros desenvolvimento social e econômico, favorecendo a expansão do intercâmbio com a troca de conhecimento e tecnologias (ASSUMPÇÃO, 2007). Diante dos diversos problemas enfrentados pelos empresários brasileiros para se estabelecerem competitivamente no mercado nacional, tornou-se imperativo a busca por novas opções de fazer negócios. O Brasil apresenta um cenário altamente burocrático e com alta tributação, a importação de bens de consumo pelos pequenos empreendedores, que se deparam com essas e outras dificuldades, sendo assim, este estudo objetiva identificar os desafios enfrentados por microempresas do varejo para a importação de bens de consumo da China. Em consonância 
com o objetivo geral proposto, foram delineados três objetivos específicos, que são: verificar na percepção dos empresários o impacto da comunicação e aspectos culturais entre brasileiros e chineses no processo de importação; mensurar o impacto da carga tributária no valor final dos produtos importados pelas microempresas pesquisadas; relacionar as dificuldades encontradas no processo de habilitação das microempresas para operarem no comercio internacional, na visão dos gestores.

A pesquisa se justifica já que pretende identificar os entraves enfrentados por microempresas do varejo para a importação de bens de consumo da China, visando minimizar os desembolsos para melhorar os resultados econômicos e financeiros destas MPEs.

\section{REFERENCIAL TEÓRICO}

Este capítulo destina-se a embasar os assuntos abordados nesta pesquisa, servindo como uma familiarização a respeito do tema abordado, assim apresenta o ponto de vista de diversos autores sobre os principais assuntos em questão, proporcionando bases científicas com a finalidade de oferecer credibilidade ao presente trabalho.

\section{Comércio Internacional}

Conforme Mochón (2007), o fluxo de bens, serviços, capital, trabalho e tecnologia se internacionalizaram e alteraram o ritmo da atividade comercial e do crescimento econômico mundial. Sobre o mesmo tema, Trípoli e Prates (2016) entendem a palavra comércio como sendo a transferência de um produto ou serviço para outro agente e cuja movimentação obrigatoriamente implica no recebimento de algum valor percebidamente monetário, ou até mesmo outro bem ou serviço. Ainda segundo os autores, em termos gerais, o comércio pode ser definido como uma transação de troca. Trípoli e Prates 
(2016) afirmam que o ato de compra e venda entre dois ou mais agentes de uma mesma região ou nação configura-se como atividade comercial.

No entanto, se esta prática acontece entre dois ou mais agentes que estão em nações diferentes, esta é uma transação de comércio internacional, incluindo ai a exportação e a importação que Tripoli e Prates (2016) definem da seguinte forma:

Exportação é a saída de bens ou serviços de uma nação com destino a outras nações, o que implica o recebimento monetário por isso, ou seja, ocorre a entrada de divisas. Já a importação é a entrada em nossa nação de bens ou serviços oriundos de outras nações, decorrendo dai a saída de divisas. Portanto, a importação é o simétrico da exportação (TRIPOLI; PRATES, 2016, p. 32).

Segundo Maluf (2000), alguns fatores influenciam na decisão de uma nação de realizar transações internacionais, destacando entre eles o fornecimento de recursos, a necessidade de equilibrar a balança de pagamentos, a atualização tecnológica, a busca de recursos para financiar as atividades internas, a diversificação de mercado, a ampliação da pauta de importações e exportações, e o desenvolvimento social através da geração de empregos. O autor ainda define o comércio internacional como "o intercâmbio de bens e serviços entre países, resultante das especializações na divisão internacional do trabalho e das vantagens comparativas dos países". (MALUF, 2000, p. 23).

De acordo com Keedi (2007), a importância da importação é a ampliação de mercados, pois a empresa que importa deixa de atuar apenas no mercado interno, diversificando as opções de fornecedores e minimizando os riscos do impacto de uma possível crise nacional, como aumento de preços e políticas protecionistas governamentais. A importação é definida na compra de produtos no exterior por países que deles necessitam, podendo assim oferecer diferentes alternativas aos con- 
sumidores, aumentando a competitividade com relação a seus concorrentes, suprindo a constante necessidade de inovação e agregando a sua capacidade produtiva.

\section{Comércio exterior brasileiro}

O mundo vive um período politicamente conturbado, porem de expansão econômica. Enquanto isso, o Brasil, país singular por conta de suas riquezas naturais e mão de obra abundante, há mais de 20 anos não consegue traduzir estes fatores a seu favor e expressa esse cenário através de um dos mais baixos índices de crescimento econômico do mundo (LOURES; SCHLEMM; CASTOR, 2013). De acordo com Loures, Schlemm e Castor (2013) durante muitos anos, o Brasil manteve sua economia praticamente fechada para o comércio internacional, adotando políticas econômicas protecionistas destinadas a beneficiar a exportação em detrimento das importações, visando com isso uma manutenção superavitária da balança comercial. Este quadro começou a mudar no início da década de 90, pois de acordo com o Ministério da Indústria, Comércio Exterior e Serviços (MDIC, 2017), nesta época o Brasil implementou a sua abertura comercial com a redução de tarifas de importação e reformulação dos incentivos às exportações. Os fluxos comerciais internacionais se intensificaram e foi criado o Mercado Comum do Sul - MERCOSUL, assim como nesta mesma década também foi instituída a Organização Mundial de Comércio (OMC), organismo multilateral responsável pela regulamentação do comércio internacional. De acordo com o MDIC (2017), foi a partir de 2000, que o comércio exterior brasileiro passou a operar em um ritmo mais vigoroso. $\mathrm{O}$ crescimento econômico mundial, o aumento dos preços internacionais de produtos básicos, a diversificação dos mercados importadores e a maior produtividade da indústria nacional são fatores que 
favoreceram o dinamismo das exportações brasileiras, que passou a atingir sucessivos recordes.

Neste contexto, Pinheiro, Markwald e Pereira (2002), afirmam que nas últimas décadas o Brasil conseguiu mudar de forma significativa o seu comércio exterior, pois até os anos 60 o país direcionava sua produção majoritariamente à exportação de produtos primários, tais como café, que no início do século era responsável por $70 \%$ de toda exportação do país. Atualmente a economia brasileira é mais complexa e diversificada, apresentando exportações de produtos industrializados, que na década de 60 correspondiam à apenas 5\% do total das exportações do país e em 2005 já representavam $60 \%$ de todo comércio exterior do Brasil, o que evidencia avanços econômicos provocados pela modernização do setor industrial.

Como fator fundamental para o incentivo do comércio exterior, Vazquez (2009), destaca a remoção de barreiras que protegem a indústria nacional, facilitando a internacionalização das empresas brasileiras, fazendo-as ainda mais competitivas no cenário internacional, em razão da necessidade de manter sua participação no mercado interno e a competitividade em escala internacional, utilizando-se da alternativa de importação de produtos e mercadorias.

A partir de 2015, o mundo ingressou num período social e economicamente conturbado, onde se observou o aumento do número de refugiados de guerra e a existência de ameaças terroristas, alguns dos grandes desafios mundiais, que vêm acompanhados da deterioração de importantes economias emergentes. O resultado deste quadro é o fraco desempenho do comércio internacional, a diminuição do fluxo de capitais e a queda dos preços de commodities, que explicam a redução crescimento da economia mundial. (EPE, 2016).

Neste cenário desfavorável, o relatório de 2016 do Ministério das Relações Exteriores, mostra que os principais produtos

ReMAS - Revista Metodista de Administração do Sul, v. 2, N. 2, 2017 
exportados pelo Brasil em 2016 são os minérios, combustíveis e pastas de madeiras e os produtos importados pelo Brasil são embarcações flutuantes, máquinas elétricas e mecânicas. Ainda no ano de 2016, os maiores parceiros comerciais do Brasil para exportações foram: China, Estados Unidos, Argentina, Países Baixos e Alemanha; já nas importações as cinco principais origens de produtos são a China, Estados Unidos, Alemanha, Argentina e Coréia do Sul (MRE, 2016).

Se considerados os BRICS, sigla que se refere às economias emergentes do Brasil, Rússia, Índia, China e África do Sul, os piores desempenhos em 2015 foram de Rússia e Brasil, com queda de $3,7 \%$ e 3,8\%, respectivamente. Porém, a desaceleração também atingiu a China que fechou o ano com crescimento do PIB abaixo de 7\%, menor resultado dos últimos anos. A redução das demandas da China, dado o menor investimento e menor participação da indústria, afetará os preços internacionais das commodities e a balança comercial de diversos países, incluindo o Brasil, já que a China é um forte parceiro comercial, como será visto no próximo item.

\section{Comércio Brasil - China}

De acordo com Sebben (2011) o início do século XXI marca a aproximação comercial entre o Brasil e China. Esta aproximação se insere em um contexto onde a China se tornou cada vez mais próxima das economias latino americanas de uma forma geral. Isto ocorre, pois o país asiático se tornou um exportador, que demanda matérias-primas e energia, se consolidando como polo de investimentos e irradiador de dinamismo comercial e financeiro.

O Brasil vende para a China soja em grãos e sementes, minérios combustíveis, pastas de madeira e celulose, carnes, açúcar, cobre, peles, aço e ferro e máquinas mecânicas e compra máquinas elétricas e mecânicas, químicos orgânicos, 
embarcações flutuantes destinadas principalmente a indústria do petróleo, ferro e aço, plásticos, vestuário exceto malhas, automóveis e instrumentos de precisão (EPE, 2016). Este quadro de desequilíbrio onde o Brasil vende produtos primários e compra produtos de tecnologia, não é recente, pois Becard (2011) já destacava o desequilíbrio na qualidade do intercâmbio comercial, pois em 2009, os produtos básicos representaram 77\% das exportações Brasil - China, enquanto que os produtos industrializados somaram 95\% das importações.

Entretanto não só de grandes exportações e importações se faz o comércio exterior entre Brasil e China, no ramo do varejo onde atuam os pequenos importadores e consórcios de importadores alguns produtos se destacam, como as utilidades domesticas, artigos de decoração e bazar, roupas, brinquedos, games além de eletrônicos e acessórios, principalmente os de ponta como os smartphones e seus acessórios como capas protetoras e fones de ouvido. Paiva (2014) afirma que a partir de 2001, com a adesão da China à OMC, ocorreu a redução de impostos sobre operações de exportação, que aliada aos altos investimentos chineses em inovação e tecnologia, resultaram em produtos de qualidade e maior valor do conteúdo, impulsionando a indústria chinesa perante o mercado global. Contribuem para isto o baixo custo unitário do produto e a enorme escala de produção que converteram a China num grande exportador mundial.

Este comércio internacional está sujeito a diversas regras, onde, segundo Vazquez (2009), com a intenção de uniformizar o tratamento de informações advindas do comércio exterior:

Com a nova política econômica e a abertura do comércio internacional, o Governo Federal determinou o desenvolvimento de um sistema de informações que integrasse as atividades dos principais órgãos públicos envolvidos com o Comércio Exterior: DECEX, BACEN e SRF, de modo a uniformizar o tratamento dado ao fluxo de informações de importação e de exportação (VAZQUEZ, 2009, p. 141).

ReMAS • Revista Metodista de Administração do Sul, v. 2, N. 2, 2017 
De qualquer sorte, o importador precisa saber que a importação é uma atividade sujeita a exigências administrativas, aduaneiras e cambiais, e que nas operações de comércio exterior são cobrados impostos e tributos que oneram a aquisição de bens e serviços no exterior e, que a sua introdução no território nacional é controlada por meio de legislação específica.

Aspectos culturais presentes nas relações de comerciais entre Brasil e China

Para Minervini (2008) a cultura é um conjunto de normas adquiridas com o passar do tempo, fundamentada em atitudes, valores e percepções de uma determinada sociedade. Para o autor, as diferenças culturais podem influenciar diretamente o sucesso de negociações comerciais. Fatores como costumes, religião, superstições, valores, linguagem corporal, idioma, entre outros, constituem aspectos que devem ser levados em consideração quando existe a intenção de estabelecer relações comerciais com pessoas ou organizações de outros países.

O processo de negociação internacional significa mais que pura e simplesmente efetivar negócios, também significa conhecer, entender e compartilhar a diversidade cultural dos povos, bem como sua localização geográfica e aspectos econômicos para adaptar a forma de comportamento, possibilitando a realização de negócios internacionais (ROBLES; NOBRE, 2016)

Quando uma empresa inicia o processo de internacionalização, está sujeita a diversos riscos advindos deste processo, tais como risco cambial, risco comercial e um dos principais riscos que é diversidade intercultural. Esse risco intercultural pode ser exemplificado como uma situação ou evento em que uma das partes, ou ambas, faça uma má interpretação de valores ou costumes. Essa má interpretação pode ser decorrente da diferença de idiomas, do modo de vida, costumes, dentre 
outros. A diversidade cultural pode causar falhas na comunicação, dando origem a estratégias inadequadas de negócios e relações ineficazes com clientes e fornecedores (CAVUSGIL; KNIGHT; RIESENBERGER, 2010).

Para Rosenbloom (2002), as diferenças socioculturais são fatores importantes nas negociações internacionais, podendo exercer o mesmo efeito que barreiras comerciais. Para superar estes desafios, as organizações devem buscar compreender a cultura e o idioma dos países onde tenham interesse de fazer negócios. Neste contexto, no que diz respeito a China, Rosenbloom (2002), expõe que é uma nação gigante, situado no lado oriental do planeta e, embora estejamos em plena era das comunicações, ainda é um país pouco conhecido, coberto de mistérios que despertam a curiosidade sobre a sua história e origens. A China é o maior país em desenvolvimento, possuindo a maior população e o terceiro maior território do mundo, além de, nos últimos vinte anos, vir apresentando os maiores índices de crescimento econômico.

De acordo Rosenbloom (2002), a China viveu durante um longo período sob um regime socialista extremamente fechado e, aos poucos, implementou medidas econômicas que promoveram a sua abertura para o mercado global, surpreendendo o mundo ao adaptar pontos conflitantes entre capitalismo de mercado e socialismo. Ainda segundo o autor, nas últimas décadas a China passou a desempenhar um papel de grande destaque mundial, principalmente na esfera econômica, influenciando as esferas política e social.

Em meio ao rápido crescimento econômico, os chineses têm como prioridade fazer negócios com seus compatriotas. Esta diferença de mentalidade deve gerar fatos conflitantes no futuro próximo, uma vez que muitos bens comercializados no mundo todo têm origem na China, como ressalta Shin (2008): 
Nos últimos anos a China foi chamada de 'fábrica do mundo', pois passou a concentrar uma parcela significativa de tudo o que é fabricado no planeta. A variedade e os números da produção são impressionantes. Mais da metade dos produtos de informática, DVDs e televisores LCD, sapatos, meias e confecções, oitenta por cento dos insumos de vitamina $C$ e de lâmpadas fluorescentes, um terço do aço e do cimento (SHIN, 2008, p. 25).

De acordo com Trevisan (2009), para os chineses ter uma ampla e boa rede de relacionamentos é parte essencial para o sucesso de um negócio. O bom relacionamento com clientes e fornecedores é construído pacientemente através de exaustivos encontros sociais, tais como jantares de negócios, onde os interessados em construir vínculos comerciais comem, bebem e trocam presentes. O acordo implícito nesse tipo de encontro é a interdependência mútua e a possível troca de favores. Para a autora, quem tem a intenção de estabelecer um vínculo comercial de confiança com um chinês, deve tomar cuidado de jamais colocá-lo em uma situação constrangedora, apontando seus erros ou fraquezas em público.

Segundo Costa e Santos (2011), uma característica marcante do povo chinês é a paciência, e isto também tem a sua representatividade no mundo dos negócios, sendo pratica comum que os representantes das organizações sejam submetidos a vários encontros e longas reuniões antes da concretização de negócios com organizações chinesas.

Conforme Trevisan (2009), outro fator que dificulta a aproximação de culturas ocidentais à China é o idioma. $\mathrm{O}$ mandarim, idioma oficial da China, é predominantemente monossilábico que possui quatro tons com as quais as palavras são pronunciadas. Desta forma, uma única palavra monossílaba pode ser pronunciada de quatro formas e possuir inúmeros significados distintos. Esses tons apresentam diferenças extremamente sutis à percepção dos ocidentais, porem, 
podem mudar completamente o significado de uma palavra ou expressão. Além de apresentar essa grande peculiaridade quanto à fonética, o idioma também apresenta elevado grau de complexidade quanto à escrita, visto que não possui alfabeto no qual a aglutinação de letras formam sons específicos. $\mathrm{Na}$ escrita chinesa não há letras, mas sim símbolos que possuem significado e que são chamados de caracteres ou ideogramas, pelo simples fato de trazerem contidos em si uma ideia.

\section{METODOLOGIA}

Este estudo foi desenvolvido utilizando-se da metodologia descritiva, já que seu propósito foi descrever os desafios enfrentados por três microempresas do varejo para a importação de bens de consumo da China. Este tipo de pesquisa para Gil (2002) é aquela que objetiva a descrição de características de determinada população, de modo a estabelecer relações entre as variáveis. A pesquisa utilizou uma abordagem qualitativa com um procedimento de levantamento de campo, que de acordo com Diehl e Tatim (2004) é um dos procedimentos adequados às pesquisas descritivas, pois verificam as opiniões e atitudes de uma população, obtendo dados que representem a população analisada. Gil (2002) complementa, expondo que o levantamento de campo se caracteriza pelo questionamento direto às pessoas, ou seja as informações a cerca do problema estudado são solicitadas às pessoas envolvidas e em seguida é realizada a análise quantitativa, exatamente como se procedeu aqui.

A pesquisa foi realizada com três gestores de microempresas de importação: uma sediada na cidade de Canoas (RS); outra em Curitiba (PR); e a terceira em Maracajú (MS). Estes gestores configuraram os sujeitos da pesquisa, pois como esclarecem Marconi e Lakatos (2010), nas pesquisas qualitativas, não se determina uma amostra da população, se estabelece apenas um tempo delimitado e um sujeito, a partir do qual haverá a

ReMas - Revista Metodista de Administração do Sul, v. 2, N. 2, 2017 
coleta dos dados que serviram de base para o estudo, sendo os mesmos escolhidos por acessibilidade ou conveniência.

O instrumento de coleta adotado foi uma entrevista de igual teor para os três pesquisados, baseada em um roteiro semi-estruturado, composto de 20 perguntas abertas, e posteriormente ocorreu a análise e explanação dos dados obtidos, sendo estas atividades distintas, mas relacionadas. Com o intuído de alcançar os objetivos propostos por este trabalho, foi realizada a análise interpretativa além da comparação dos dados obtidos com as entrevistas com o material apresentado no referencial teórico do presente trabalho.

\section{RESULTADOS E DISCUSSÃO DA PESQUISA}

Este item apresenta a discussão dos resultados obtidos buscando identificar os desafios enfrentados por três microempresas do varejo para a importação de bens de consumo da China.

Com relação ao impacto da comunicação e aspectos culturais entre brasileiros e chineses no processo de importação, na percepção de três microempresários, primeiro objetivo específico desta pesquisa, o entrevistado A apontou que, em sua percepção, os impactos da comunicação e dos aspectos culturais são muito poucos, e o entrevistado B completou afirmando que:

Eu nunca enfrentei problemas com aspectos culturais entre brasileiros e chineses, pois morei por muitos anos na China onde estudei e aprendi os costumes locais. Esse fator eu considero um diferencial competitivo na minha empresa, pois eu mesmo consigo negociar com meus fornecedores e não necessito do auxilio de intermediários, diminuído os custos com o processo e potencializando os resultados de minhas importações (ENTREVISTADO B, 2017).

O Entrevistado $\mathrm{C}$ corroborou as respostas dadas pelos outros dois pesquisados, expondo que não percebe nenhum 
impacto que possa atrapalhar o processo, haja vista que existem inúmeras empresas brasileiras que prestam serviço de assessoria em importação e exportação, sendo muitas dessas empresas situadas na China. Os entrevistados afirmaram serem poucos esses impactos causados pela comunicação e aspectos culturais no processo de importação de bens de consumo da China.

O autor buscou verificar as principais dificuldades enfrentadas pelos microempresários com relação à comunicação com seus fornecedores, ao passo que o entrevistado A informou que acredita que o idioma é o fator mais evidente quando se fala em dificuldades visto que a grande maioria dos microempresários não conhece outra língua senão o Português. Já para o entrevistado B, o idioma e os costumes chineses representam as maiores dificuldades com relação a comunicação, salientando que os microempresários que iniciam a comunicação com seus fornecedores chineses sofrem um grande choque linguístico e cultural em um primeiro momento.

Em contraponto, o entrevistado C afirma não ter sofrido dificuldades por ter iniciado seu contato com fornecedores chineses utilizando-se de parceria com uma empresa brasileira especializada na China, abrandando o choque linguístico e cultural sofrido por outros empresários que decidiram se aventurar sozinhos no mercado chinês. Neste contexto, Trevisan (2009) expõe que o idioma representa uma barreira e dificulta a aproximação de culturas ocidentais à China, afirmação esta, confirmada pelos entrevistados que perceberam o idioma como uma das dificuldades na abordagem com seus fornecedores.

Buscou-se verificar se a grande diferença entre os idiomas não consiste em uma barreira importante no processo de negociação, ao que o entrevistado A expos que para dirimir possíveis conflitos entre o idioma falado pelo importador e o idioma falado pelo exportador, se pode utilizar um terceiro idioma que é o inglês, sendo esta a língua universal no con-

REMAS - Revista Metodista de Administração do Sul, v. 2, N. 2, 2017 
texto dos negócios internacionais. Já para o entrevistado B, se o importador não consegue se comunicar eficientemente com seus fornecedores e também não utiliza o serviço de terceiros para tal, o risco de inviabilizar a negociação é muito alto. $\mathrm{O}$ entrevistado $\mathrm{C}$ concordou que a diferença entre os idiomas consiste em um empecilho no processo de negociação.

As respostas dos entrevistados convergem integralmente com a bibliografia, pois como destaca Minervini (2008), se a pessoa ou empresa com a qual se está negociando não fala o idioma do importador, ou até mesmo um terceiro idioma comum falado entre ambas as partes, torna-se indispensável o auxilio de um intérprete, preferencialmente nativo no idioma com o qual se pretende negociar.

Ao se verificar as principais dificuldades encontradas no processo de negociação, levando-se em consideração as diferenças entre a cultura e costumes de chineses e brasileiros, o entrevistado A salientou que sua principal dificuldade se relacionou ao valor pago pelas mercadorias como sendo microempresário, levando em consideração que para os chineses oferecerem benefícios nos preços praticados seria necessário comprar em larga escala.

Para o entrevistado B, as principais dificuldades encontradas no processo de negociação estão os obstáculos em estabelecer um vínculo de confiança com os fornecedores e a percepção de que os chineses oferecem preferência e privilégios para importadores que também sejam chineses, não importando que o volume negociado, seja similar entre um importador brasileiro e um comprador chinês, visto que historicamente a sua cultura é bastante fechada para relações de confiança mútua com ocidentais.

O entrevistado $C$ afirmou que sua principal dificuldade foi encontrar fornecedores com os quais se possa estabelecer parcerias de longo prazo, pois de acordo com o mesmo, os 
chineses são muito imediatistas e buscam lucro rápido, muitas vezes não pensando em realizar parcerias com microempresários, mesmo que estes tenham grande potencial de crescimento no médio e no longo prazo.

Em um paralelo com os autores pesquisados, Robles e Nobre (2016) expõem que o processo de negociação internacional significa mais do que simplesmente efetivar negócios, mas também significa conhecer, entender e compartilhar a diversidade cultural dos povos, bem como sua localização geográfica, idioma, costumes e aspectos sociais e econômicos para adaptar a forma de comportamento, possibilitando a realização de negócios internacionais com sucesso e perspectivas de manter relacionamentos comerciais duradouros.

$\mathrm{Na}$ sequência os entrevistados foram questionados quanto a alternativas viáveis para resolver possíveis dificuldades enfrentadas com a comunicação durante o processo de negociação com seus fornecedores. Conforme o entrevistado A as principais medidas a serem tomadas para sanar estas dificuldades seriam, primeiramente, a conscientização do microempresário quanto a sua qualificação para que o mesmo aprenda inglês ou até mesmo o idioma falado pelos fornecedores, bem como maiores incentivos governamentais para os pequenos empresários se qualificarem.

O entrevistado C salienta que, se o empresário não possui conhecimento em idioma comum falado entre comprador e fornecedor, a solução imediata é a contratação de serviços de tradutor ou assessoria em comércio exterior que auxiliem durante a negociação, diminuindo os riscos de possíveis prejuízos. O entrevistado B, corroborou a opinião dos entrevistados A e $C$, afirmando que:

No meu ponto de vista, para quem trabalha com negócios internacionais o melhor é sempre investir no aprendizado de idiomas falados por países reconhecidamente atuantes no comércio Internacional, tais

REMAS - Revista Metodista de Administração do Sul, v. 2, N. 2, 2017 
como Inglês, Espanhol e Mandarim, porem, esta é uma solução com resultados a longo prazo visto que o aprendizado de um idioma estrangeiro requer tempo, o que muitas vezes nós microempresários não dispusemos. A alternativa mais rápida e viável então seria contratar o serviço de empresa especializada no mercado local com o qual se pretende negociar. Agindo desta forma, o custo total com o processo pode aumentar, mas as chances de sucesso do negocio também aumentam em igual proporção (ENTREVISTADO B, 2017).

A opinião de Trevisan (2009) converge com a dos entrevistados, o autor aponta que o idioma é um fator que dificulta muito a aproximação de culturas ocidentais à China, devido ao mandarim, idioma falado pelos chineses, ser um idioma de alto grau de complexidade, tanto na fala, quanto na escrita.

Buscando responder ao problema proposto no segundo objetivo específico, de mensurar o impacto da carga tributária no valor final dos produtos importados pelas três microempresas pesquisadas, se iniciou com a percepção dos entrevistados quanto a existência de outros países que pudessem oferecer benefícios similares aos obtidos no processo de importação de bens de consumo da China. Neste ponto o entrevistado A afirmou que costuma importar diversos tipos de categorias de produtos, como utensílios de uso doméstico, artigos de decoração, dentre outros e que estes produtos são constituídos de diferentes tipos de matéria prima. $\mathrm{O}$ governo Brasileiro adota estratégias de proteção da indústria nacional quando desconfia que determinados produtos advindos de determinados países estejam entrando no país com valor abaixo do praticado no mercado internacional. Esse é o caso de utensílios de cozinha feitos de aço inox e artigos de cerâmica, como canecas e pratos, com origem da China. O governo Brasileiro criou uma sobretaxa para esses produtos fabricados na China, inviabilizando as importações em pequena escala. Desta forma o entrevistado A, afirma que teve de buscar alternativas em outros países como Turquia, 
Índia e Tailândia, porem não conseguiu encontrar os mesmos benefícios encontrados na China, pois nos países citados não logrou êxito em comprar pequenas quantidades e o custo com a logística foi muito mais elevado para viabilizar a compra.

A percepção do entrevistado B, com relação ao mesmo questionamento é de que países menos desenvolvidos e com mão de obra barata são opções viáveis no futuro, mas que atualmente não vê outro país que ofereça as mesmas condições favoráveis como a China devido a sua infraestrutura e poder econômicos já estabelecidos.

O entrevistado C, por sua vez, concorda em parte com os outros dois entrevistados afirmando que, em sua opinião, existem outros países onde se encontram vantagens similares as da China. Para ele, levando em consideração a qualidade dos produtos manufaturados, países como Taiwan, Coreia do Sul, Estados Unidos e Alemanha são alternativas viáveis para a busca de fornecedores. Em contraponto, se o fator levado em consideração for o preço do produto, as opções ficariam mais restritas a países subdesenvolvidos e com mão de obra barata, tais como Vietnam, Camboja e Bangladesh.

Para Paiva (2014), com a adesão em 2001 da China à Organização Mundial do Comércio, ocorreu a redução de impostos sobre operações de exportação e importação de bens de consumo, que aliada aos altos investimentos chineses em inovação e tecnologia, resultou em produtos de qualidade e maior valor agregado, impulsionando a indústria chinesa frente ao mercado global. Aliadas aos incentivos governamentais chineses a exportação e a sua infraestrutura bem desenvolvida, o baixo custo unitário do produto e a enorme escala de produção converteram a China em um grande exportador mundial.

Os entrevistados buscaram elucidar quais os impactos da carga tributária no valor final dos produtos importados da China ao passo que o entrevistado A demonstrou que: 
O impacto da carga tributária é altíssimo, algo em torno de $70 \%$ do valor de compra do produto. A incidência pode ser ainda maior caso o produto se enquadre em alguma categoria sobretaxada pelo governo federal, pois os impostos são cobrados em cascata, o que acaba piorando a situação do importador. Somos taxados sobre o valor pago na mercadoria na origem, adicionando o custo com logística, seguro marítimo ou aéreo, além de demais taxas alfandegárias. Após calculado esse valor, pagamos primeiramente os impostos federais como Imposto de Importação, IPI, PIS e COFINS e após pagos estes encargos, soma-se ainda a alíquota de ICMS, que incide sobre o valor total já atualizado com os demais encargos citados.(ENTREVISTADO A, 2017).

O entrevistado B ratifica a opinião do entrevistado A, afirmando que a carga tributária é responsável por mais da metade do custo total de uma importação. Esse percentual costuma variar bastante devido ao fato de que cada produto possui uma carga tributária própria, dependendo única e exclusivamente de sua classificação fiscal. Ainda de acordo com o entrevistado B, alguns produtos podem sofrer sobretaxação para impedir a concorrência desleal com os fabricantes nacionais de similares, enquanto, determinadas categorias de produtos podem até receber isenção fiscal para estimular a importação. Normalmente, esses produtos que oferecem isenção fiscal não são produzidos pelo mercado local e precisam de estímulo para serem importados.

O entrevistado $C$ respalda a opinião dos outros dois entrevistados, sinalizando que a carga tributária no Brasil é muito pesada e dificulta as importações, muitas vezes até chegando a inviabilizar a compra de produtos oriundos da China.

Para Brogini (2013), na legislação fiscal brasileira vigente, a tributação é uma regra e a concessão de benefícios fiscais passou a ser uma exceção. Cabe então ao microempresário buscar alternativas na legislação que possam ajudar a minimizar os efeitos que a pesada carga tributária brasileira tem sobre as organizações. Tal atitude configura uma importante 
ferramenta de planejamento estratégico que pode representar o sucesso de determinada atividade comercial.

Outro questionamento apresentado ao entrevistados foi com relação a percepção dos entrevistados quanto aos impactos que o aumento de determinada alíquota de imposto teria no valor final dos produtos importados da China. Ao que o entrevistado A afirmou que o aumento de qualquer alíquota de imposto tem impacto totalmente negativo, pois diminui a já fragilizada competitividade de microempresários frente à concorrência com empresas de maior porte já estabelecidas há mais tempo no mercado e que possuem relativo poder de barganha junto a seus fornecedores.

O entrevistado B complementa o testemunho do entrevistado $A$, levantando uma consideração importante com a afirmação de que dependendo do percentual de aumento da carga tributária, muitas vezes, pode se tornar inviável a importação de determinados produtos e esse aumento das alíquotas muitas vezes se da pela iniciativa do governo federal de proteger a indústria nacional, o que de certa forma pode ter efeito benéfico para o importador, pois o mesmo pode obter determinada mercadoria na indústria nacional por valor competitivo com relação ao praticado no exterior. Todavia o entrevistado B afirma que não são todas as categorias nas quais se percebe essa competitividade nos preços, sendo os produtos feitos de plástico os que mais representam o exemplo, visto que a indústria termoplástica nacional é bastante competitiva frente aos preços de produtos importados.

Já para o entrevistado $C$, a carga tributária praticada no Brasil, não encontra mais espaço para aumentos, pois já é altíssima. Um aumento dessas alíquotas inviabilizaria o negócio de importação e uma desestabilização da economia visto que o Brasil não é auto-suficiente na produção de bens de consu- 
mo e a importação muitas vezes é a única forma de atender a demanda por produtos que não são fabricados aqui.

Para Mochón (2007), o principal efeito percebido quando do aumento de uma alíquota de imposto é refletido diretamente no comportamento do consumidor. Para o autor, o estabelecimento de um imposto ou, aumento da alíquota de imposto já existente, incide diretamente no preço final do bem comercializado, encarecendo-o e acarretando na diminuição do volume de vendas. Este fator impacta diretamente na economia, no curto e longo prazo, gerando impactos negativos no crescimento econômico do país.

Contrapondo o questionamento anterior, o autor buscou verificar na percepção dos entrevistados, os impactos que uma redução das alíquotas de imposto teriam no valor final dos produtos importados da China. A este questionamento o entrevistado A alega ser difícil analisar por esta perspectiva tendo em vista que muito raramente ocorrem reduções nas alíquotas, mas dependendo da redução poderia acarretar na diminuição de algo em torno de 30\% no valor final da mercadoria. Em sua percepção, o impacto seria extremamente benéfico para todas as partes envolvidas no processo de importação, tendo em vista que o preço final teoricamente seria mais baixo, o importador poderia comprar uma quantidade maior e vende-la por um valor inferior, mantendo sua margem de lucro e ganhando na venda em maior escala. Sob a ótica do consumidor, essa redução no preço traria potencial para compra de outros produtos, retroalimentando o sistema.

Para o entrevistado B, uma redução na carga tributária traria uma redução proporcional no valor final dos produtos. Em contrapartida o entrevistado $C$ garante que se houvesse redução em alguma alíquota de imposto inerente ao processe de importação, o principal beneficiado seria o importador, pois o mesmo poderia aumentar o seu lucro. Desta forma o impacto 
da redução não seria visto no volume de vendas, mas sim na margem de lucro praticada pelo microempresário.

Conforme Brogini (2013) a redução de alíquotas de tributos fiscais é um expediente bastante comum adotado pelo governo federal quando este pretende estabelecer pacotes de benefícios fiscais a determinados setores da economia nacional. Os motivos pelos quais esses benefícios fiscais são concedidos podem ser os mais variados, dentre eles, a redução de barreiras tarifárias para a importação de produtos oriundos de países signatários de acordos bilaterais de comércio internacional.

Foi também questionado junto aos entrevistados sobre a forma com a qual os tributos incidentes no processo de importação contribuem para o desenvolvimento das microempresas brasileiras, na percepção dos entrevistados, e para os entrevistados $A$ e $B$, os tributos incidentes no processo de importação de bens de consumo não contribuem de forma alguma para o desenvolvimento das microempresas. O entrevistado C, em concordância com os outros dois microempresários, ainda afirma que a função social para as quais os impostos e taxas foram criados não é cumprida e que o microempresário precisa desembolsar para garantir seus direitos básicos como contribuinte.

Para Brogini (2013), os tributos são a principal fonte de financiamento da atividade estatal, sendo estes necessários e indispensáveis para que o Estado possa garantir o cumprimento de suas obrigações para com os contribuintes e promover e sustentar o desenvolvimento social e econômico do país.

Buscando relacionar as dificuldades encontradas no processo de habilitação das três microempresas para operarem no comércio internacional, na visão dos gestores, se buscou a estimativa de espera não inferior a 10 dias uteis, além do deslocamento até a unidade mais próxima da Receita Federal que, no seu caso, ficava a $160 \mathrm{~km}$ de distância da sua empresa. 
De acordo com o a Receita Federal (2017) o sistema integrado de comércio exterior (Siscomex) foi implementado com o intuito de dar mais agilidade, celeridade e transparência a todos os processos pertinentes a atividade de importação e exportação de bens de consumo.

\section{CONSIDERAÇÕES FINAIS}

Com relação ao impacto da comunicação e aspectos culturais entre brasileiros e chineses no processo de importação, foram apontados pelas empresas pesquisadas como sendo de pouca representatividade no contexto geral. Os gestores que não estão acostumados com a linguagem e costumes dos fornecedores chineses optam por utilizar o serviço de assessoria especializada no mercado chinês que auxilia no contato e negociação entre as partes. O gestor que possuía conhecimento prévio do idioma e costumes não apontou qualquer dificuldade em relação aos aspectos culturais.

Com relação ao impacto da carga tributária no valor final dos produtos importados pelas microempresas pesquisadas verificou-se que, na percepção dos gestores, a carga tributária incidente no processo de importação é responsável por grande parte do custo final das mercadorias, em alguns casos chegando até a ser responsável por mais da metade do valor final de determinado bem importado.

Quanto as dificuldades encontradas no processo de habilitação das microempresas para operarem no comércio internacional, os gestores pesquisados apontaram o processo de habilitação no Radar, a falta de preparo dos fiscais, o desconhecimento da legislação e a exigência demasiada de documentos comprobatórios que aumentam o tempo necessário para a obtenção da licença.

Desta forma objetivo principal de identificar os desafios enfrentados por microempresas do varejo para a importação 
de bens de consumo da China de acordo com as entrevistas com gestores são inúmeras, tais como: diferenças linguísticas e culturais entre Brasil e China, falta de conhecimento da legislação fiscal e aduaneira, pesadas cargas tributárias incidentes na importação de bens de consumo, excesso de burocracia por parte do Governo Federal e a evidente falta de competitividade da indústria nacional.

\section{REFERÊNCIAS}

ASSUMPÇÃO, Rossandra Mara. Exportação e Importação: conceitos e procedimentos básicos. Curitiba: Ibpex. 2007.

BRASIL. Secretaria da Receita Federal do Brasil. Ato declaratório Executivo Coana $\mathbf{n}^{\mathrm{o}}$ 3, de $\mathbf{1}^{\mathrm{o}}$ de junho de 2006. Ministério da Fazenda. 2006. Disponível em: <www.cnpq.br/c/document_library/get_file? uuid=1d4f1b87-420e-452b-90cf>. Acesso em: 12 maio 2017.

BRASIL. Secretaria da Receita Federal do Brasil. Regimes aduaneiros especiais. 2017. Disponível em: <https://idg.receita.fazenda.gov.br/orientacao/ aduaneira/regimes-e-controles-especiais/regimes-aduaneiros-especiais $>$. Acesso em: 12 maio 2017.

BRASIL. Secretaria da Receita Federal do Brasil. Sistema Integrado de Comércio Exterior - SISCOMEX. 2014. Disponível em: <https://idg.receita. fazenda.gov.br/orientacao/aduaneira/importacao-e-exportacao/sistema-integrado-de-comercio-exterior-siscomex> Acesso em: 12 maio 2017.

BRASIL. Senado Federal. Plano Collor, abertura de mercados e impeachment. 2007. Disponível em: https://www12.senado.leg.br/noticias/ materias/2007/03/15/plano-collor-abertura-de-mercados-e-impeachment-marcaram-primeiro-governo-eleito-apos-o-regime-militar Acesso em: 23 de outubro 2017.

BROGINI, Gilvan. Tributação e benefícios fiscais no comércio exterior. Curitiba: Intersaberes, 2013.

CAVUSGIL, Tamer; KNIGHT, Gary; RIESENBERGER, John R. Negócios Internacionais: estratégia, gestão e novas realidades. São Paulo: Pearson Prentice Hall, 2010. 
COSTA, Armando João Dalla; SANTOS, Elson Rodrigo de Souza. Estratégias e negócios das empresas diante da internacionalização. Curitiba: Ibpex, 2011.

DIEHL, Astor Antônio; TATIM, Denise Carvalho. Pesquisa em ciências sociais aplicadas: métodos e técnicas. São Paulo: Prentice-Hall, 2004.

GIL, Antônio Carlos. Como elaborar projetos de pesquisa. 4 ed. São Paulo: Atlas, 2002.

KEEDI, S. Logística de transporte internacional. 3. ed. São Paulo: Aduaneiras, 2007.

LOURES, Rodrigo Costa da Rocha; SCHLEMM, Marcos Mueller; CASTOR, Belmiro Valverde Jobim. Para o Brasil voltar a crescer: evidencias, reflexões e caminhos. Curitiba: Intersaberes, 2013.

MALUF, Sâmia Nagib. Administrando o comércio exterior do Brasil. São Paulo: Aduaneiras, 2000.

MARCONI, Marina de Andrade; LAKATOS, Eva Maria. Fundamentos de metodologia científica. 7.ed. São Paulo: Atlas, 2010.

MDIC. Ministério de Desenvolvimento, Indústria e Comercio Exterior. < http://www.mdic.gov.br/comercio-exterior> Acesso em: 05 jun. 2017.

MINERVINI, Nicola. O exportador: ferramentas para atuar com sucesso no mercado internacional. 5.ed. São Paulo: Pearson Prentice Hall, 2008.

MOCHÓN, Francisco. Princípios de economia. São Paulo: Pearson Prentice Hall, 2007.

PINHEIRO, Armando Castelar; MARKWALD, Ricardo; PEREIRA, Lia Walls. O desafio das exportações. Rio de Janeiro: BNDES, 2002.

PORTAL SISCOMEX. O portal SISCOMEX. 2017. Disponível em: <http:// portal.siscomex.gov.br/conheca-o-portal/O_Portal_SISCOMEX>. Acesso em: 12 maio 2017.

RECEITA FEDERAL. Receita Federal do Brasil. Disponível em: <http://idg. receita.fazenda.gov.br/orientacao/aduaneira/manuais/habilitacao $>$. Acesso em: 05 jun. 2017.

ROBLES, Léo Tadeu; NOBRE, Marisa. Logística Internacional: uma abordagem para integração de negócios. Curitiba: Intersaberes, 2016.

ROSEMBLOOM, Bert. Canais de Marketing: uma visão gerencial. São Paulo: Atlas, 2002. 


\section{OS DESAFIOS ENFRENTADOS POR MICROEMPRESAS \\ DO VAREJO PARA A IMPORTAÇÃO \\ DE BENS DE CONSUMO DA CHINA}

SEBRAE, Serviço Brasileiro de Apoio as Micro e Pequenas Empresas. Disponível em: < https://www.sebrae.com.br/sites/PortalSebrae/artigos/saiba-como-se-habilitar-para-usar-o-siscomex >. Acesso em: 05 jun. 2017.

SEBRAE, Serviço Brasileiro de Apoio às Micro e Pequenas Empresas. As micro e pequenas empresas na exportação brasileira. Brasília: SEBRAE, 2010.

SEBRAE-SP. Empreendedor individual: perguntas e respostas. São Paulo: SEBRAE, 2011.

SHIN, Wong, K. A China explicada para brasileiros. São Paulo: Atlas, 2008. TREVISAN, Claudia. Os chineses. São Paulo: Contexto, 2009.

TRIPOLI, Ângela Cristina Kochinski; PRATES, Rodolfo Coelho. Comércio internacional: teoria e prática. Curitiba: InterSaberes. 2016.

VAZQUEZ, José Lopes. Comércio exterior brasileiro. 9. ed. São Paulo: Atlas, 2009. 